\title{
Quality of life in children and adolescents with allergic rhinitis
}

\author{
Carlos Henrique Martins da Silva ', Taís Estevão \\ da Silva ${ }^{2}$, Nívea Macedo O. Morales ${ }^{3}$, Karla P. \\ Fernandes ${ }^{4}$, Rogério M. C. Pinto ${ }^{5}$
}

Keywords: adolescents, children, quality of life, rhinitis.

\section{Summary}

\begin{abstract}
A llergic rhinitis (AR) remains a significant pediatric health problem because of the burden of uncontrolled symptoms on daily activities and on general well being. Aim: to assess the impact of AR on health-related quality of life (HRQL) of children and adolescents using a generic instrument, the Child Health Questionnaire (CHQ - PF50). Methods: Between January and November 2004, parents or caregivers of 23 children and adolescents with AR without comorbidities and with positive prick tests for at least one air allergen were invited to participate of a cross-sectional study and asked to answer the self-administered CHQ-PF50. The scores were compared to those of healthy children and adolescents. Results: Patient scores were lower $(\mathrm{p}<0.05)$ than healthy subsets in both the physical and psychosocial summaries and in most of the CHQ-PF50 scales $(p<0,05)$, except for the "change in health" scale. The size effect was higher in the physical score compared to the psychosocial summary score. Conclusions: allergic rhinitis has a global negative impact on the HRQL of children and adolescents, with major repercussions in physical function; AR also negatively affects family relations.
\end{abstract}

${ }^{1}$ Doctor, professor of the Pediatrics Department, Faculdade de Medicina da Universidade Federal de Uberlândia. ${ }^{2}$ Resident in pediatrics (second year resident in pediatrics), Universidade Federal de Uberlândia.

${ }^{3}$ Doctor, neuropediatrician of the Hospital de Clínicas da Faculdade de Medicina da Universidade Federal de Uberlândia and the Associação de Assistência a Criança Deficiente, AACD.

${ }^{4}$ Master's degree, in charge of the Child Allergology Unit of the Hospital de Clínicas da Faculdade de Medicina da Universidade Federal de Uberlândia. ${ }^{5}$ Doctor, professor at the Faculdade de Matemática da Universidade Federal de Uberlândia.

Paper submitted to the BJORL-SGP (Publishing Management System - Brazilian Journal of Otorhinolaryngology) on May 6, 2008; and accepted on October 12, 2008. cod. 5835 


\section{INTRODUCTION}

Three fundamental reasons have been given for treating patients: to prolong life, to reduce morbidity and to seek well-being. ${ }^{1}$ Until recently, the success of therapy was evaluated only according to morbimortality rates. Measurements based on physiological and laboratory tests described the severity of disease, and well-being was believed to be the natural consequence of reducing such severity. ${ }^{2-4}$ However, evidence has shown that objects parameters correlate poorly or moderately with the wellbeing of patients. A given clinical severity may have diverse effects on the well-being of different patients because of tolerance levels, health expectations and the ability to deal with disease-imposed limitations. Any evaluation should embody the subjective perceptions of patients about their own status and quality of life (QOL)., 2,56

The World Health Organization (WHO) defines QOL as "individuals' perception of their position in life in the context of the culture and value systems in which they live and in relation to their goals, expectations, standards and concerns." The term "health-related quality of life" (HRQL) derived mostly from a redefinition of health by the WHO in 1948: "a state of full physical, mental and social well-being, and not merely absence of illness or disease."

HRQL investigation includes features such as subjectivity, multidimensionality (physical, psychological and social domains) and bipolarity (positive and negative domains, such as autonomy and dependence). ${ }^{7}$ Many questionnaires for assessing the HRQL have been tested; they are classified as generic or specific., ${ }^{2,9}$

Generic instruments comprise domains applicable to many diseases and population groups; it is possible to compare diagnoses and healthy $\mathrm{x}$ ill groups. Specific instruments assess the HRQL in diseases and/or specific populations; it is more sensitive for detecting change.,10

Allergic rhinitis (AR) is one of the diseases of childhood that affects the HRQL. It is an inflammation of the nasal mucosa due to an IgE-mediated hypersensitivity reaction to specific allergens that occurs in genetically predisposed and sensitized individuals; one or more of the following symptoms may be present: nose block, watery rhinorrhea, sneezing, and nasal itching. ${ }^{11}$

The prevalence of this disease has increased in recent decades partly due to environmental exposure to allergens, altered life styles (more time spent in closed environments), and social and economic factors. World statistics show $30 \%$ to $40 \%$ prevalence in children and teenagers. Studies in Brazil have shown a 33\% and 34\% prevalence in school children aged 6-7 years and 13-14 years. ${ }^{11}$ The prevalence was $24 \%$ among school-aged children (6-7 years) in the city of Uberlandia. ${ }^{12}$

Although there is a trend to underestimate the repercussions of AR on the QOL of individuals - because it is a benign disease that rarely requires hospitalization, surgery or complex interventions ${ }^{1,6}$ - AR may cause physical, psychological and social changes in patients, which need to be investigated. ${ }^{2,3,13-15}$

Assessments of the impact of AR on the HRQL became more common in the 1990s. ${ }^{1,4}$ The first such studies were carried out in adults, using generic and specific instruments. ${ }^{16-19}$ There were fewer studies done in children and teenagers, only with specific questionnaires. ${ }^{20,21}$ Nascimento Silva ${ }^{22}$ adapted and validated a specific questionnaire (RQLQ) for Brazilian adolescents with rhinitis. The current recommendation is to include HRQL studies using specific and generic instruments in clinical trials on chronic respiratory diseases, as well as investigation of objective clinical parameters such as pulmonary functions tests (asthma) and symptom evaluation scales (rhinitis). ${ }^{23,24}$

The purpose of this study was to assess the impact of AR on the HRQL of children and teenagers by applying a generic instrument - the Child Health Questionnaire (CHQ-PF50).

\section{SERIES AND METHOD}

A cross-sectional study was undertaken from January to November 2004, following approval by the local Research Ethics Committee (n⿳ 095/2002).

\section{Participants}

Invitations were sent to parents or guardians of children aged over 5 years and teenagers with a diagnosis of AR for at least one year, based a the clinical history of suggestive symptoms (sneezing, rhinorrhea, nasal itching and/or obstruction) in suggestive circumstances (exposure to known allergens) and with positive immediate hypersensitivity skin tests for at least one of the following aeroallergens: Blomia tropicalis, Dermatophagoides pteronyssinus, Dermatophagoides farinae, storage acarid mites, fungi, pollen, feathers, Blatella germanica, wool, dog and cat epithelium.

Patients with other chronic diseases or comorbidities that might have altered the HRQL investigation, such as asthma, atopic eczema, sinusitis, or food allergy, patients using medication that could alter the skin tests, and patients that refused the skin tests were excluded.

A control group was formed from a database of healthy children and teenagers with no history of respiratory allergies, evaluated during validation of the Brazilian version of the CHQ-PF50;21 these children were matched for age and sex in a 3:1 proportion for this study.

\section{"Child Health Questionnaire - CHQ-PF50"}

The "50-item, parent completed short form, Child Health Questionnaire" (CHQ-PF50) is a generic questio- 
nnaire for assessing the HRQL, applicable to children aged over 5 years and teenagers, in the perspective of parents or guardians. It was developed in Boston, US, between 1990 and 1996, ${ }^{25}$ and adapted culturally and validated for the Brazilian population..$^{26,27}$ This instrument consists of 50 items distributed in 4 simple scales and 11 multiple item scales; it encompasses 11 child domains and 4 family domains (Table 1 ). Scores range from 0 to 100; highest scores indicate better functioning or feeling. There are two summary component scores of physical and psychosocial health. ${ }^{25}$

\section{Procedure}

Parents and guardians signed a free informed consent form adapted to the Portuguese language and answered a protocol with demographic data (sex, age, education level and number of siblings of child, education of informant and family monthly income) and information about the disease (severity and duration). The CHQ-PF50 questionnaire was applied just before or immediately after a consultation, using a self-application technique.

Patients were asked to indicate an overall state of discomfort due to AR on an analog visual scale (AVS) measuring $100 \mathrm{~mm}$ with no subdivisions, where 0 was lack of discomfort and 100 was extreme discomfort. Discomfort due to each symptom (nasal block, sneezing, coryza and nasal itching) was scored from 0 to 6 , where 0 was absence and 6 was extreme discomfort. Categories are subdivisions of 24 points, as follows: 0 (no discomfort), 1-8 (mild discomfort), 9-16 (moderate-severe discomfort) and 17-24 (severe discomfort).

Patients were classified according to the severity of $\mathrm{AR}$ as mild and moderate-severe, according to the consensus criteria of the Allergic Rhinitis and its Impact on Asthma (ARIA). ${ }^{28}$

CHQ-PF50 scores of AR patients were compared with the control group scores and correlated with severity and overall discomfort of AR (AVS) and degree of discomfort due to each symptom.

The reliability of the instrument - verification of measurement errors and accuracy of scales and domains - was established by internal consistency, the degree by which items are interrelated.

\section{Statistical analysis}

Descriptive statistical analysis was applied to characterize social and demographic features of participants. Internal consistency was measured using the Cronbach $\alpha$ coefficient. Cronbach's $\alpha$ coefficient is based on the number of items in a scale and their homogeneity. For comparisons of groups, 0.5 to 0.7 (or more) minimal reliability measures are recommended.
Student's t test was applied for comparing the scores of AR patients and healthy children and teenagers.

The effect size was applied to assess the magnitude of differences found in each scale and in the summary scores; the control group mean was subtracted from the mean of the study group and the result was divided by the standard deviation of the control group. A 0.20 to 0.49 result was considered small, a 0.50 to 0.79 result was considered moderate, and a result of 0.80 or more was considered large. ${ }^{29}$

The point biserial correlation coefficient was applied to verify correlations among scales and summary scores in the CHQ and the AVS.

Pearson's correlation coefficients (quantitative variables) and Spearman's correlation coefficients (qualitative variables) were applied to verify correlations among scales and summary scores of the CHQ and disease severity, and discomfort categories due to each symptom.

The significance level was 0.05 .

\section{RESULTS}

\section{Participants}

There were 44 patients with a diagnosis of AR (without asthma or other comorbidities) in the outpatient unit. Two of these abandoned the study, 6 were aged below 5 years, 4 did not return the questionnaire, 5 had negative skin tests, and 4 did not answer the questionnaire, and were all excluded from the study. At the end there were 23 questionnaires available for analysis. Twenty-one patients had persistent AR, and two patients had intermittent AR.

Informants were mostly mothers (86.95\%). The mean age of patients was 9.22 years; most were male (78.26\%). Table 2 shows additional features of the sample.

Cronbach's alpha coefficients were above 0.7 , except for the perception of health scale (0.3).

Scores in the study group were lower compared to the control group, except for the change in health scale. The difference between groups was not significant only in the scales general behavior and family activities $(p=0.108$ and $p=0.081$ ). The size effect was significant in summary scores and in 10 scales, and moderate in 5 scales; it was higher in the physical summary score (1.83) compared to the psychosocial summary score (0.89) (Table 3 ).

The analog visual scale was positively correlated and significant in the general behavior scale $(\mathrm{r}=0.42)$ and negative and significant in the change in health scale $(\mathrm{r}=$ -0.52) (Table 4).

Disease severity and discomfort due to each symptom did not correlate significantly with CHQ scores. 
Table 1. Interpretation of domain scores of the CHQ PF-50

\begin{tabular}{|c|c|c|}
\hline Domain & Low score & High score \\
\hline General health assessment & In general, the child's health is poor & In general, the child's health is excellent \\
\hline Physical functioning* & $\begin{array}{l}\text { Child is limited in carrying out all physical } \\
\text { activities, including self-care, due to health } \\
\text { issues }\end{array}$ & $\begin{array}{l}\text { Child carries out all types of activities, } \\
\text { including those that require effort, with no } \\
\text { limits due to health issues }\end{array}$ \\
\hline Limitation due to emotional aspects* & $\begin{array}{l}\text { Child is limited in carrying out schoolwork } \\
\text { and activities with friends due to emotional } \\
\text { or behavioral issues }\end{array}$ & $\begin{array}{l}\text { Child is not limited by emotional or beha- } \\
\text { vioral issues in schoolwork and activities } \\
\text { with friends }\end{array}$ \\
\hline Limitation due to the physical function* & $\begin{array}{l}\text { Child is very limited in carrying out scho- } \\
\text { olwork or activities with friends due to } \\
\text { physical health issues }\end{array}$ & $\begin{array}{l}\text { Child is not limited by physical health } \\
\text { issues in schoolwork or activities with } \\
\text { friends }\end{array}$ \\
\hline Bodily pain* & Child has severe and frequent pain & Child has no bodily pain \\
\hline Behavior* & $\begin{array}{l}\text { Child often discusses, finds it hard to } \\
\text { concentrate, lies, steals, is obstinate or } \\
\text { irritated/willful }\end{array}$ & $\begin{array}{l}\text { Child does not discuss, has no concentra- } \\
\text { tion problems, has not lied, stolen, beco- } \\
\text { me obstinate or irritated/willful }\end{array}$ \\
\hline General behavior & $\begin{array}{l}\text { Child behavior is poor compared to other } \\
\text { children }\end{array}$ & $\begin{array}{l}\text { Child's behavior is excellent compared to } \\
\text { other children }\end{array}$ \\
\hline Mental health* & $\begin{array}{l}\text { Child cries episodically, feels alone, ner- } \\
\text { vous, bothered or annoyed }\end{array}$ & $\begin{array}{l}\text { Child has no episodes of crying, does not } \\
\text { feel alone, nervous, bothered or annoyed }\end{array}$ \\
\hline Self-esteem* & $\begin{array}{l}\text { Child is not satisfied with abilities, appea- } \\
\text { rance, relationships and life in general }\end{array}$ & $\begin{array}{l}\text { Child is satisfied with abilities, appearan- } \\
\text { ce, relationships and life in general }\end{array}$ \\
\hline Perception of health & $\begin{array}{l}\text { Parents believe that their child's health is } \\
\text { poor and tends to become worse }\end{array}$ & $\begin{array}{l}\text { Parents believe that their child's health is } \\
\text { excellent and will continue to be }\end{array}$ \\
\hline Change in health & $\begin{array}{l}\text { Child's health is poorer now compared to } \\
\text { a year ago }\end{array}$ & $\begin{array}{l}\text { Child's health is better now compared to } \\
\text { a year ago }\end{array}$ \\
\hline Emotional impact on parents * & $\begin{array}{l}\text { Parents are greatly concerned or bothered } \\
\text { with the physical or psychosocial health of } \\
\text { the child }\end{array}$ & $\begin{array}{l}\text { Parents are not worried or bothered with } \\
\text { the physical or emotional health of the } \\
\text { child }\end{array}$ \\
\hline Time impact on parents* & $\begin{array}{l}\text { Parents feel limited in their own needs due } \\
\text { to the physical or psychosocial health of } \\
\text { the child }\end{array}$ & $\begin{array}{l}\text { Parents do not feel limited in their own } \\
\text { needs because of the physical or psycho- } \\
\text { social health of the child }\end{array}$ \\
\hline Family activities* & $\begin{array}{l}\text { The child's health often limit/interrupts } \\
\text { family activities or causes distress }\end{array}$ & $\begin{array}{l}\text { The child's health never limits/interrupts } \\
\text { family activities or causes distress }\end{array}$ \\
\hline Family cohesion & $\begin{array}{l}\text { The ability of the family to understand } \\
\text { each other is poor }\end{array}$ & $\begin{array}{l}\text { The ability of the family to understand } \\
\text { each other is excellent }\end{array}$ \\
\hline
\end{tabular}

*Questions refer only to the past four weeks

\section{DISCUSSION}

This is the first study to assess the HRQL in children and teenagers with AR with the generic questionnaire CHQ-PF 50.

The internal consistency reliability of the instrument items was adequate except for the perception of health scale, as also observed in the Brazilian version of the CHQ-PF50 for a healthy population, for subjects with juvenile idiopathic arthritis and with cerebral palsy. ${ }^{27,30,31}$ This result may suggest issues with the cultural adaptation of this instrument or difficulty in understanding items of the scale.

The results show that AT has a negative multidimensional impact on the HRQL. The repercussion is more pronounced in the physical health domain compared to the psychosocial domain (larger size effect in the physical summary score); this has been described in other 
Table 2. General characteristics of participants

\begin{tabular}{ll}
\hline \multicolumn{1}{c}{ Characteristics } & \multicolumn{1}{c}{ Participants $(\mathrm{n}=23)$} \\
\hline Mean age in years (range) & $9,2(5-14)$ \\
Male sex (\%) & $18(78,3 \%)$ \\
Mean education level in years (range) & $3,2(0-7)$ \\
Mean number of siblings (range) & $1(0-5)$ \\
Severity of rhinitis (ARIA), n (\%) & $5(21,7 \%)$ \\
Mild & $18(78,3 \%)$ \\
Moderate - Severe & $5,2(0,7-14)$ \\
Mean duration of disease in years (range) & $53(1,1-100)$ \\
General degree of discomfort caused by rhinitis (analog visual scale), mean (range) & \\
Degree of discomfort of main symptoms, $n$ (\%) & $8(34,8 \%)$ \\
Mild & $12(52,2 \%)$ \\
Moderate - severe & $3(13,0 \%)$ \\
Severe & \\
\hline
\end{tabular}

Table 3. CHQ-PF50 scores in patients and controls

\begin{tabular}{|c|c|c|c|c|c|c|}
\hline \multirow[b]{2}{*}{ Scales and summaries - CHQ-PF50 } & \multicolumn{2}{|c|}{ Controls $(n=69)$} & \multicolumn{2}{|c|}{ Patients $(n=23)$} & \multirow[b]{2}{*}{$p$ value* } & \multirow[b]{2}{*}{ Size effec } \\
\hline & Mean & $\begin{array}{l}\text { Standard } \\
\text { deviation }\end{array}$ & Mean & $\begin{array}{l}\text { Standard } \\
\text { deviation }\end{array}$ & & \\
\hline General health & 93,26 & 12,03 & 62,17 & 25,26 & 0,000 & 2,58 \\
\hline Physical functioning & 98,47 & 8,93 & 88,52 & 21,78 & 0,043 & 1,11 \\
\hline $\begin{array}{l}\text { Limitations due to emotional as- } \\
\text { pects }\end{array}$ & 97,42 & 8,76 & 85,85 & 23,05 & 0,031 & 1,32 \\
\hline $\begin{array}{l}\text { Limitations due to the physical } \\
\text { function }\end{array}$ & 98,06 & 12,13 & 86,23 & 21,70 & 0,019 & 0,97 \\
\hline Bodily pain or discomfort & 96,96 & 9,28 & 70,43 & 19,88 & 0,000 & 2,86 \\
\hline Behavior & 78,17 & 12,52 & 65,46 & 19,74 & 0,007 & 1,01 \\
\hline General behavior & 85,00 & 16,13 & 75,65 & 25,37 & 0,108 & 0,58 \\
\hline Mental health & 78,95 & 11,85 & 70,87 & 17,17 & 0,014 & 0,68 \\
\hline Self-esteem & 93,06 & 13,46 & 82,44 & 23,35 & 0,048 & 0,79 \\
\hline Perception of health & 79,01 & 11,90 & 64,00 & 17 & 0,000 & 1,26 \\
\hline Change in health & 67,54 & 23,84 & 84,78 & 19,57 & 0,001 & $-0,72$ \\
\hline Emotional impact on parents & 83,70 & 21,93 & 63,76 & 30,42 & 0,007 & 0,91 \\
\hline Time impact on parents & 93,30 & 15,85 & 79,03 & 27,74 & 0,030 & 0,90 \\
\hline Limitations in family activities & 89,19 & 14,26 & 82,71 & 17,95 & 0,081 & 0,45 \\
\hline Family cohesion & 78,48 & 18,28 & 61,09 & 30,78 & 0,016 & 0,95 \\
\hline Summary score of physical health & 56,65 & 5,33 & 46,89 & 10,53 & 0,000 & 1,83 \\
\hline $\begin{array}{l}\text { Summary score of psychosocial } \\
\text { health }\end{array}$ & 54,03 & 6,54 & 48,23 & 7,72 & 0,001 & 0,89 \\
\hline
\end{tabular}

* Student's t test 
Table 4. Correlation among CHQ-PF50 scores and the analog visual scale

\begin{tabular}{|c|c|c|}
\hline \multirow{2}{*}{ Scales and summaries - CHQ-PF50 } & \multicolumn{2}{|c|}{ AVS } \\
\hline & r & p-value \\
\hline General health & 0,10 & 0,62 \\
\hline Physical functioning & 0,32 & 0,12 \\
\hline Limitations due to emotional aspects & 0,24 & 0,28 \\
\hline Limitations due to the physical function & 0,29 & 0,17 \\
\hline Bodily pain or discomfort & $-0,34$ & 0,11 \\
\hline Behavior & 0,05 & 0,82 \\
\hline General behavior & 0,42 & 0,04 \\
\hline Mental health & 0,22 & 0,29 \\
\hline Self-esteem & 0,13 & 0,54 \\
\hline Perception of health & $-0,04$ & 0,84 \\
\hline Change in health & $-0,52$ & 0,00 \\
\hline Emotional impact on parents & 0,28 & 0,19 \\
\hline Time impact on parents & 0,30 & 0,16 \\
\hline Limitations in family activities & 0,17 & 0,42 \\
\hline Family cohesion & $-0,11$ & 0,60 \\
\hline Summary score of physical health & 0,15 & 0,49 \\
\hline Summary score of psychosocial health & 0,09 & 0,68 \\
\hline
\end{tabular}

AVS $=$ analog visual scale

studies of adults and children. ${ }^{17,18,21}$ The lowest score was found in the control group in the change in health scale, as expected for a healthy population with no change in health across time.

Some studies ${ }^{16,20,21,32}$ have documented AR-related situations that caused most discomfort to patients: nasal symptoms, associated symptoms (headache, tearing, increased thirst, weariness/fatigue, concentration difficulty, insomnia); emotions (irritation, frustration due to limits caused by the disease on daily activities, disquiet, impatience, anger, nervousness, shame due to nasal symptoms), and practical problems (repeatedly scratching and blowing the nose, carrying handkerchiefs, using medication).

In children, nasal symptoms and practical matters may bother school colleagues and cause embarrassment and labeling. Schoolwork may be affected due to distraction, fatigue, irritability, side effects of medication, or absenteeism. Therapeutic control measures to avoid contact with allergens may limit recreational activities and contact with colleagues, leading to social isolation. ${ }^{4}$

A Brazilian study of teenagers showed that physical symptoms (mostly nasal), rather than emotional factors, were the most frequently mentioned items as causing discomfort. Other discomfort factors mentioned were weariness, malaise, thirst, anxiety, nervousness, use of me- dication, and embarrassing situations due to symptoms. ${ }^{22}$ The results of family-related domains indicate that the disease has a negative impact on the family. Studies of chronic diseases in childhood have shown that these conditions may affect the QOL of families as follows: lack of sleep, fatigue, absence from work, cancellation of vacations, interference on social life, and financial costs. Some parents may feel guilt, become anxious or overprotective, or even hostile towards the child, which may have a negative effect on the family group., 433

The correlation between the AVS and the change in health domain suggest that increased discomfort due to AR as perceived by the child is correlated with a poorer perception of improvement in health as seen by the parents, which may be a challenge for successful therapy in patients with greater discomfort.

Non-agreement between general behavior and behavior scales in the correlation with the AVS may be due to a different approach towards the theme; the former scale compares the child's behavior with that of other children in one item only, while the latter includes five situations, questioning the child's behavior in each one. These results suggest that parents do not perceive behavior differences when comparing their children with other children, although they may be able to report a worse 
behavior in daily situations. Specific instruments evaluating this domain may provide more accurate information.

\section{Limitation of this study}

Although genetic studies of the HRQL make it possible to compare patients with different chronic conditions, they may be indifferent to changes in specific conditions, since their focus is not a specific disease. ${ }^{9}$ This methodological limitation, inherent to generic instruments, may explain the conflicting results we found.

A representative filling in a HRQL questionnaire is a situation that, a priori, conflicts with the underlying principle of seeking an evaluation by the patient him or herself about their status. Children vary in the development of basic understanding of meanings and functions of the words health and disease, which may preclude effective communication. Agreement among answers by children and those of parents or guardians remains controversial, but has been confirmed in some studies. ${ }^{10,34}$

AR often is associated with other allergies, especially asthma. Our study aimed, however, to investigate the impact of AR singly. Such rigor in the inclusion criteria restricted the participation of subjects with other atopic conditions, which was reflected in the sample size.

\section{CONCLUSION}

AR causes a global negative impact on the HRQL of children and teenagers, altering mostly the physical function, according to the perception of parents or guardians, and affects negatively the family group.

\section{REFERENCES}

1. Juniper EF. Can quality of life be quantified? Clin Exp All Rev. 2002;2(2):57-60.

2. Juniper EF. Impact of upper respiratory allergic diseases on quality of life. J Allergy Clin Immunol. 1998;101 Suppl 2:386-91.

3. Thompson A, Juniper EF, Meltzer EO. Quality of life in patients with allergic rhinitis. Ann Allergy Asthma Immunol. 2000;85(5):338-48.

4. Meltzer EO. Quality of life in adults and children with allergic rhinitis. J Allergy Clin Immunol. 2001;108 Suppl 1:45-53.

5. De Graff-in 't Veld T, Koenders S, Gerrelds IM, Gerth Van Wijk R. The relationships between nasal hyper reactivity, quality of life, and nasal symptoms in patients with perennial allergic rhinitis. J Allergy Clin Immunol. 1996;98(3):508-13.

6. Juniper EF. Measuring health-related quality of life in rhinitis. J Allergy Clin Immunol. 1997;99 Suppl 2:742-9.

7. The WHOQOL Group. The World Health Organization Quality of Life Assessment (WHOQOL): position paper from the World Health Organization. Soc Sci Med. 1995;41:1403-9.

8. Gerth Van Wijk R. Allergy: A global problem. Quality of life. Allergy. 2002;57(12):1097-110.

9. Guyatt GH, Feeny DH, Patrick DL. Measuring health-related quality of life. Ann Intern Med. 1993;118(8):622-9.
10. Jenney MEM, Campbell S. Measuring quality of life. Arch Dis Child. 1997;77(4):347-54

11. Consenso sobre rinites. Rev Bras Otorrinolaringol. 2000;66 Suppl 10:4-34.

12. Guimarães R, Ceccon CL, Fernandes DT, Pinto LF, Faria TL, Ambrosio MR et al. Prevalência da rinite alérgica em escolares de 6 a 7 anos na cidade de Uberlândia, ISAAC fase 3. Anais da XVI Semana Científica da Medicina;2003 Set 17-20;Uberlândia, Brasil. p. 31.

13. Scadding GK, Bousquet J. Introduction. Allergy. 2007;62 Suppl 85:3-5.

14. Canonica GW, Bousquet J, Mullol J, Scadding GK, Virchow JC. A survey of the burden of allergic rhinitis in Europe. Allergy. 2007;62 Suppl 85:17-25.

15. Schatz M. A survey of the burden of allergic rhinitis in the USA. Allergy. 2007;62 Suppl 85:9-16.

16. Juniper EF, Guyatt GH. Development and testing of a new measure of health status for clinical trials rhinoconjunctivitis. Clin Exp Allergy. 1991;21(1):77-83.

17. Bousquet J, Bullinger M, Fayol C, Marquis P, Valentin B, Burtin B. Assessment of quality of life in patients with perennial allergic rhinitis with the French version of the SF-36 health status questionnaire. J Allergy Clin Immunol. 1994;94(2 Pt 1):182-8.

18. Meltzer EO, Nathan RA, Selner JC, Storms W. Quality of life and rhinitic symptoms: Results of a nationwide survey with the SF36 and RQLQ questionnaires. J Allergy Clin Immunol. 1997;99 Suppl:815-9

19. Leynaert B, Neukirch C, Liard R, Bousquet J, Neukirch F. Quality of life in allergic rhinitis and asthma. A population-based study of young adults. Am J Respir Crit Care Med. 2000;162(4):1391-6.

20. Juniper EF, Guyatt GH, Dolovich J. Assessment of quality of life in adolescents with allergic rhinoconjunctivitis: development and testing of a questionnaire for clinical trials. J Allergy Clin Immunol. 1994;93(2):413-23.

21. Juniper EF, Howland WC, Roberts NB, Thompson AK, King DR, Math B. Measuring quality of life in children with rhinoconjunctivitis. J Allergy Clin Immunol. 1998;101(2 Pt 1):163-70.

22. Silva MGN. Adaptação e validação do questionário "RQLQ" para avaliação da qualidade de vida em crianças e adolescentes com rinite alérgica [tese de mestrado]. São Paulo(SP): Universidade Federal de São Paulo;1999.

23. Passalacqua G, Canônica GW, Baiardini I. Rhinitis, rhinosinusitis and quality of life in children. Pediatr Allergy Imunnol. 2007;18 Suppl 18:40-5.

24. Kremer B, Klimek L, Bullinger M, Mösges L. Generic or diseasespecific quality of life scales to characterize health status in allergic rhinitis? Allergy. 2001;56:957-63.

25. Landgraf JM, Abetz L, Ware JE Jr. The Child Health Questionnaire: A user's manual. 2nd ed. Boston (MA): The Health Act;1999.

26. Machado CSM, Ruperto N, Silva CHM, Ferriani VPL, Roscoe I, Campos LMA et al. For the Pediatric Rheumatology International Trials Organization (PRINTO) The Brazilian version of the Childhood Health Assessment Questionnaire (CHAQ) and the Child Health Questionnaire (CHQ). Clin Exp Rheumatol. 2001;19 Suppl 23:25-9.

27. Gomes DC. Adaptação e validação para a língua portuguesa do questionário genérico de avaliação de qualidade de vida - "50item, parent complete short form, Child Health Questionnaire" (CHQ-PF50) [tese de mestrado]. Uberlândia (MG): Universidade Federal de Uberlândia;2001. 
28. Bousquet J, Khaltaev N, Cruz AA, Denburg J, Fokkens WJ, Togias A et al. Allergic rhinitis and its impact on asthma (ARIA) 2008 update (in collaboration with World Health Organization, GA2LEN and AllerGen). Allergy .2008;63 Suppl 86:8-160.

29. Health outcomes methodology symposium. Glossary Med Care. 2000;38 Suppl 2:7-13.

30. Landgraf JM, Maunsell E, Speechley KN, Bullinger M, Campbell S, Abetz L, et al. Canadian-French, German and UK versions of the Child Health Questionnaire: methodology and preliminary item scaling results. Qual Life Res. 1998;7(5):433-45.
31. Morales NMO, Silva CHM, Frontarolli AC, Araújo RRH, Rangel VO, Pinto RMC et al. Psychometric properties of the initial Brazilian version of the CHQ-PF50 applied to the caregivers of children and adolescents with cerebral palsy. Qual Life Res. 2007;16(3):437-44.

32. Meltzer EO. Does rhinitis compromise night-time sleep and daytime productivity? Clin Exp All Rev. 2002;2(2):67-72.

33. Mccormick MC, Stemmler MM, Athreya BH. The impact of childhood rheumatic diseases on the family. Arthritis Rheum. 1986;29(7):872-9.

34. Eiser C, Morse R. The measurement of quality of life in children: past and future perspectives. J Dev Behav Pediatr. 2001; 22(4):248-56. 